\title{
Obtaining of Solid Biofuels from Plant Waste (Rview)
}

\author{
Irina G. Sudakova and Nataliya B. Rudenko* \\ Institute of Chemistry and Chemical Technology SB RAS \\ 50 Akademgorodok, Krasnoyarsk, 66036, Russia
}

Received 07.09.2015, received in revised form 17.10.2015, accepted 20.11.2015

Review of scientific publications and patents relating to the methods of producting of solid biofuels from plant waste was accomplished. It should be noted that most research were aimed at improving the existing methods for the production of briquettes and pellets from wood waste and expanding the raw material base for the production of solid biofuels through the use of non-wood plant biomass and municipal waste. It's shown the use of environmentally friendly binders based on plant polymers for the production of solid biofuels it makes possible to increase the density, strength and water resistance of the briquettes.

Keywords: solid biofuels, plant wastes, binders.

DOI: $10.17516 / 1998-2836-2015-8-4-499-513$

\section{Получение твердых биотоплив \\ из растительных отходов (обзор)}

И.Г. Судакова, Н.Б. Руденко

Институт химии и химической технологии СО РАН Россия, 660036, Красноярск, Академгородок, 50

\begin{abstract}
Выполнен обзор научных публикаций патентов, посвященных методам получения брикетированных твердых биотоплив из растительных отходов. Отмечено, что тематика выполненных исследований направлена на усовершенствование существующих методов получения брикетов и пеллет из древесных отходов и на расширение сырьевой базы для
\end{abstract}

(C) Siberian Federal University. All rights reserved

* Corresponding author E-mail address: inm@icct.ru 
производства твердого биотоплива за счет использования недревесной растительной биомассы и бытовых отходов. Показано, что применение экологически безопасных связующих на основе растительного сырья для производства твердых биотоплив дает возможность повысить плотность, прочность и водостойкость получаемых брикетов.

Ключевые слова: твердое биотопливо, растительные отходы, связующие.

\section{Введение}

Сырье растительного происхождения широко используется в мире как возобновляемый источник энергии [1-3].

По прогнозам экспертов, спрос на древесину для получения энергии в будущем возрастает, причем для энергетических целей могут использоваться отходы древесины в виде опилок, стружки и древесной пыли $[4,5]$. Значительное количество этих отходов не находит применения и вывозится в отвалы, при этом предприятия несут значительные расходы по их транспортировке и складированию. Кроме того, эти отходы могут быть экологически опасными для окружающей среды.

Использование древесных отходов лесопильного и деревообрабатывающего производств в качестве сырья или топлива экономически обоснованно только в тех случаях, когда поставщик древесных отходов и их потребитель расположены в непосредственной близости друг от друга. В противном случае стоимость транспортировки древесных отходов будет слишком велика из-за малой насыпной массы.

В качестве топлива, как правило, используют крупные кусковые отходы древесины, зачастую без предварительной сушки. Для эффективной работы лесной отрасли в настоящее время целесообразно обеспечить переработку и утилизацию древесных отходов в виде гранулированного биотоплива, что наиболее актуально для регионов, богатых лесными ресурсами [6].

Целью работы являлся сбор и анализ научно-технической информации для определения дальнейших путей совершенствования методов получения твердых биотоплив из древесных отходов с улучшенными показателями прочности и водостойкости.

\section{Виды твердого биотоплива}

Наиболее технологичный вид твердого биотоплива, изготавливаемого из возобновляемой биомассы, - пеллеты и брикеты. Брикетированные твердые топлива просты в производстве и выпускаются в основном из отходов деревопереработки и сельского хозяйства, а также из бытовых отходов. И это важно, поскольку помимо энергетической проблемы позволяет одновременно решать и вопросы утилизации отходов. Положительным аспектом при использовании твердого биотоплива служит его минимальное влияние на окружающую среду при сгорании по сравнению с классическим твердым топливом при одинаковой теплотворной способности. Твердые виды биотоплив на основе растительной биомассы (пеллеты и брикеты) выступают реальной альтернативой каменному углю и нефти [7].

В работе [8] была проведена оценка образования древесных отходов на предприятиях лесопромышленного комплекса Российской Федерации, результаты отражены в таблице. 
Таблица. Объем древесных отходов, образованных на предприятиях лесопромышленного комплекса Российской Федерации в 2012 г.

\begin{tabular}{|c|c|c|c|c|}
\hline \multirow{3}{*}{$\begin{array}{c}\text { Отрасль } \\
\text { производства }\end{array}$} & \multirow{3}{*}{$\begin{array}{c}\text { Объем } \\
\text { производства* }\end{array}$} & \multirow{2}{*}{$\begin{array}{c}\text { Объем сырья - } \\
\text { пиловочника }\end{array}$} & \multicolumn{2}{|c|}{ Отходы } \\
\hline & & & объем & $\begin{array}{c}\text { доля } \\
\text { от объема сырья }\end{array}$ \\
\hline & & тыс. $\mathrm{M}^{3}$ & тыс. $\mathrm{M}^{3}$ & $\%$ \\
\hline ВСЕГО & & 89565,9 & 35766,3 & 32,2 \\
\hline Производство целлюлозы (тыс. т) & 5393,7 & 24271,6 & 5093,2 & 21,0 \\
\hline Фанерное производство (тыс. м³) & 3149,5 & 8480,7 & 5347,3 & 59,6 \\
\hline Производство ДСП (тыс. усл. м³) & 6753,4 & 13539,4 & 2845,0 & 21,0 \\
\hline Производство ДВП (тыс. усл. м²) & 457587,0 & 4404,3 & 924,2 & 21,0 \\
\hline Деревообработка, (тыс. м³) & 4285,9 & 11169,3 & 8956,3 & 75,8 \\
\hline Лесопильное производство (тыс. м³) & 21675,7 & 27700,6 & 12600,3 & 43,0 \\
\hline
\end{tabular}

*- данные Росстата, расчеты автора [9].

Расчеты проводили на основании данных Росстата об объемах производства продукции лесопромышленным комплексом Российской Федерации в 2012 г.

Топливные брикеты (пеллеты) представляют собой спрессованный при высоком давлении и повышенной температуре древесный и растительный материал (опилки, торф, солома и др.), который в результате прессования приобретает новые, уникальные свойства, такие как плотность 1000 кг/м³ и теплотворную способность до 5000 Ккал/кг, что сопоставимо со свойствами каменного угля [6].

Основными требованиями, предъявляемыми к качеству твердого биотоплива, являются достаточно высокие влагостойкость, плотность и прочность. Это дает возможность транспортировки их на большие расстояния без изменения теплотворных свойств.

Производство твердого биотоплива, как правило, проще всего, не требует больших инвестиций и может быть организовано как в крупных, так и в малых масштабах.

Для изготовления твердого биотоплива используется любой вид возобновляемого сырья:

- древесные отходы различного происхождения;

- отходы сельскохозяйственного производства (лузга, шелуха, солома);

- бытовые отходы, канализационные стоки;

- специально выращиваемая топливная древесина и т.д.

- отходы целлюлозно-бумажного производства;

- торф $[10,11]$.

Чтобы сжигание отходов происходило эффективно, эти отходы должны иметь примерно одинаковые размеры и форму, обеспечивающие необходимый контакт с кислородом воздуха, чтобы получить наибольшую теплоотдачу. Кроме того, эти размеры и форма должны обеспечивать возможность механизации и автоматизации их подачи в топку. Для эффективного использования древесных отходов в качестве топлива применяется их прессование в пеллеты и брикеты.

Прессованное биотопливо имеет ряд преимуществ перед обычным древесным топливом:

$$
-501-
$$


- большая теплотворная способность по сравнению со щепой и с кусковыми отходами древесины;

- меньшая стоимость оборудования для котельных установок по сравнению с традиционными установками по сжиганию древесного топлива;

- возможность автоматизированной подачи топлива;

- объем склада для хранения биотоплива может быть уменьшен как минимум на 50 \% по сравнению со складом для древесной щепы [12].

Сырьевой базой для производства гранулированных пеллет и брикетов служат разные виды биомассы, обладающие достаточной энергетической ценностью и физическими свойствами, позволяющими эффективно измельчать и прессовать материал (рис.). Наиболее распространенные виды сырья для производства твердого биотоплива - это древесина (отходы лесозаготовки, отходы лесопиления и деревообработки), древесина с энергетических плантаций и отходы сельскохозяйственного производства (лузга подсолнечника, шелуха гречихи, проса, солома, тростник и т.д.).

В основе технологии производства прессованной продукции из опилок лежат сложные физико-химические процессы, происходящие в древесине под воздействием физикомеханических факторов. Изменение некоторых химических и физико-механических свойств древесины наблюдается в процессе сушки, обработке ее паром, а также при термическом воздействии. В результате воздействия физических факторов изменяется химический состав древесной массы, древесина приобретает новые свойства, необходимые для производства на ее основе различной прессованной продукции [13].

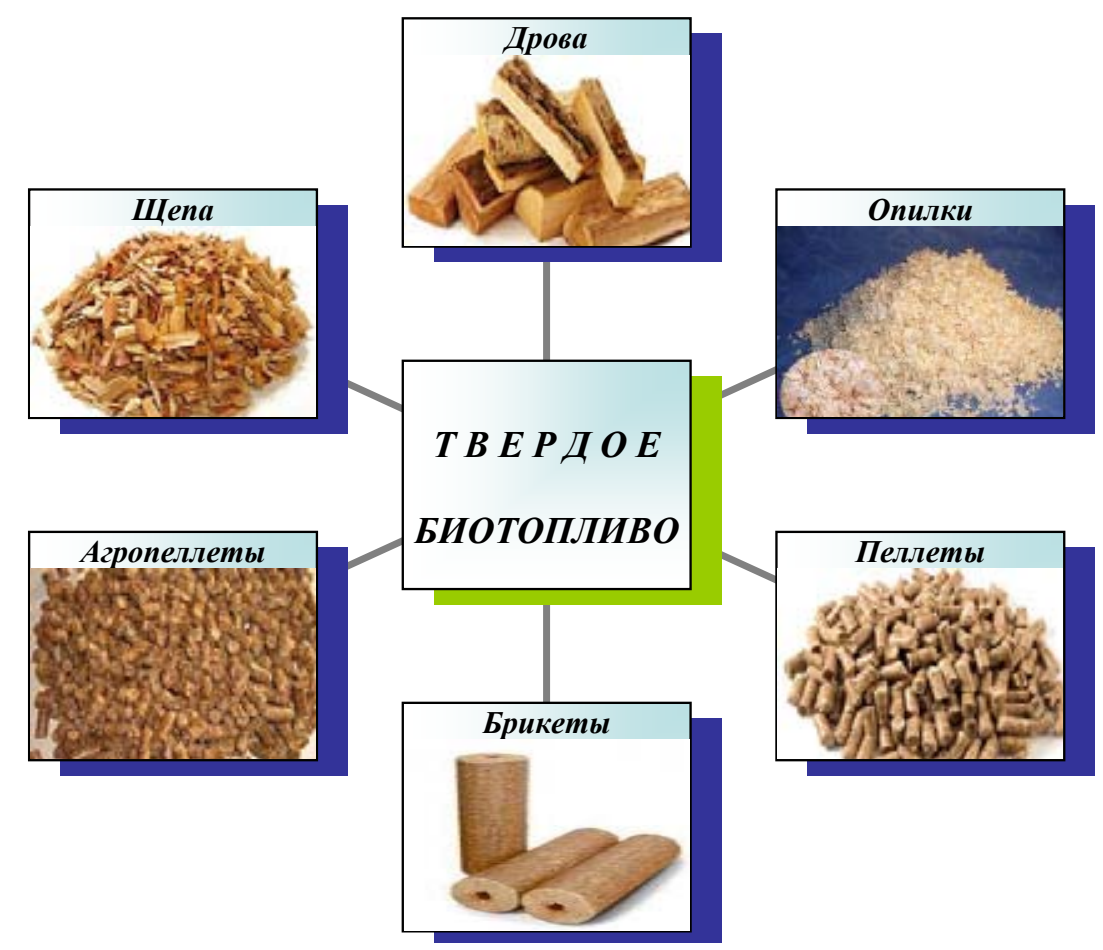

Рис. Различные виды твердого биотоплива из растительного сырья 
Так, высокие температура и давление прессования при производстве пеллет активируют лигнин [4], содержащийся в клетках растительных и древесных отходов, переводя его в пластичное состояние. Таким образом, этот лигнин и выступает в качестве внутреннего связующего. Образование термопластичного лигнина приводит к оплавлению поверхности пеллет, которая благодаря этому становится более прочной, что немаловажно для их транспортировки.

Древесные гранулы предназначены для использования в котлах и каминах для отопления частных домов, котельными жилищно-коммунального хозяйства, в системах комбинированного производства тепла и электроэнергии (КПТЭ) для теплоэнергоснабжения микрорайонов [8].

При гранулировании древесных опилок оптимальной предполагается, по данным компании California Pellet Mill, температура гранул от 88 до $102^{\circ} \mathrm{C}$. Это объясняется тем, что должно обеспечиваться плавление лигнина, которое происходит при $90{ }^{\circ} \mathrm{C}$, и отсутствовать образование водяного пара, разрывающего гранулу.

Пеллеты в отличие от обычной древесины обладают гораздо меньшей влажностью - 8 $12 \%$. Такая влажность в совокупности с достаточно высокой плотностью до $1400 \mathrm{\kappa} / \mathrm{M}^{3}$ дает возможность достигать теплотворной способности $14-23$ МДж/кг. Это больше, чем у бурого угля и торфяных брикетов [14].

Брикеты отличаются большими, чем пеллеты, размерами и по своему применению ближе к обыкновенным дровам и каменному углю, только в отличие от дров брикеты выделяют примерно в 2 раза больше тепла и эффективны в перевозке. Существует множество видов топливных брикетов, получаемых на разном оборудовании. Известны брикеты прямоугольной формы ("RUF"), восьмигранника с отверстием в середине ("Pini-kay"), брикеты цилиндрической, квадратной и восьмигранной формы ("Nielsen"). Форма и свойства брикетов разных видов зависят от их целевого предназначения, способа прессования и используемого оборудования. Наиболее распространенными являются древесные брикеты в виде «поленца» длиной 25 см круглого (диаметр 50-70 мм) или шестигранного сечения [15].

В отличие от пеллет брикеты можно сжигать в обычных печах и котлах, включая угольные, как с автоматической, так и с ручной подачей. Если для использования пеллет требуется специальный пеллетный котел, что означает замену оборудования котельной или строительство новой, то в случае с брикетами этого нет, индустриальные брикеты полноценно заменяют каменный уголь в любых масштабах.

Также у брикетов отсутствуют столь строгие, как у пеллет, требования к качеству. Наличие в сырье коры и, как следствие, повышенная зольность (в разумных пределах) не являются большой проблемой.

В отличие от производства пеллет для брикетирования порода древесины не имеет существенного значения. В то же время для лучшей настройки процесса желательно единовременно прессовать опилки одной породы древесины. Наивысшая производительность достигается при прессовании опилок из твердых пород древесины.

Брикеты, спрессованные без применения связующих веществ, по своему применению ближе к обыкновенным дровам, только в отличие от дров брикеты имеют высокую плотность. Топливные брикеты являются глубоко переработанным и экологически совершенным видом

$$
-503-
$$


топлива. Их второе название - «сухое топливо», так как влажность брикетов снижена до 10 \%. Брикетированные топлива - экологически чистый продукт и горят практически бездымно, идеально использовать их для обогрева жилых помещений [16].

Несомненным плюсом брикетов выступает постоянство температуры при сгорании на протяжении 4 ч (теплоотдача брикетов из древесных опилок 4400 ккал или 18 МДж). Экономичность брикетов подтверждает и тот факт, что закладка печи евродровами производится в три раза реже по сравнению с обычными дровами. Брикеты горят с минимальным количеством дыма, не стреляют, не искрят. Брикеты удобны в применении, эстетичны, не оставляют грязи. Для обеспечения работы котла мощностью 10 кВт в течение часа с нагрузкой $100 \%$ достаточно всего 2 кг древесных брикетов [17].

Существует две группы топливных брикетов, отличающиеся по целевому назначению : индустриальные и потребительские брикеты.

Индустриальные брикеты применяются в качестве топлива в промышленности и муниципальных котельных и электростанциях. По теплотворной способности и фракционному составу индустриальные брикеты аналогичны каменному углю, поэтому топливными брикетами можно заменять уголь в котельных без какого-либо переоборудования последних.

Индустриальные брикеты выпускаются небольшими кусками или в форме шайб, представляющих собой насыпной материал. Для индустриальных брикетов в нашей стране имеется огромный внутренний рынок, что особенно актуально для удаленных от западных границ регионов. Это связано с тем, что в отличие от пеллет для их использования не требуется установки специальных котлов и реконструкции имеющихся котельных.

Потребительские брикеты предназначены для частного рынка загородного отопления и используются в каминах, барбекю, домашних печах, банях.

Потребительские брикеты выпускаются разного вида и упаковываются в розничную упаковку. В Европе и в России наибольшей популярностью пользуются брикеты круглой формы диаметром 90 мм с центральным отверстием «Nielsen», а также брикеты прямоугольной формы «RUF».

Для получения твердого биотоплива без применения связующих в основном используют древесные отходы [18] и отходы растительной биомассы с достаточно высоким содержанием лигнина.

Однако нужно иметь в виду, что существуют и недостатки брикетов и пеллет, полученных без использования связующих, одним из которых является проблема транспортировки на большие расстояния, в ходе которого происходит разрушение значительного количества прессованного биотоплива за счет повышения влажности и как следствие снижение их теплотворных свойств [19].

\section{Применение связующих \\ при производстве твердых биотоплив}

Топливные гранулы (пеллеты) в основном производятся без добавления связующих веществ, в то время как для получения брикетов с улучшенными показателями качества используются различные добавки и связующие вещества. Большинство стандартов различных стран запрещают применение связующих для изготовления брикетов (пеллет), поскольку содержат 
жесткие экологические требования по выбросам (диоксида углерода, оксидов серы и азота, сажи и других токсичных газов) при сжигании, а также по количеству золы и ее плавкости [20].

Однако применение природных, экологически чистых связующих позволит улучшить технологические характеристики твердого биотоплива и даст возможность расширить сырьевую базу для его получения.

В качестве таких связующих может быть использован природный полимер - лигнин. Лигнин - аморфное вещество от светло-кремового до темно-коричневого цвета (в зависимости от способа выделения), молекулярная масса растворимых лигнинов от 1 до 150 тыс., плотность 1,25-1,45 г/см³. Лигнин проявляет пластические свойства при повышенном давлении и температуре, особенно во влажном состоянии. Лигнины, выделенные различными способами, отличаются по составу и свойствам как от продукта в нативной форме (протолигнина), так и друг от друга [21].

Лигнин, представляющий собой смесь нерегулярных полимеров родственного строения, в основе которых лежат близкие по строению ароматические вещества, уже давно является объектом исследований, направленных на разработку способов его использования. Наибольший интерес для получения твердого биотоплива представляют отходы гидролизного производства - гидролизный лигнин, который может служить как в качестве наполнителя в топливном композите, так и в качестве связующего при его производстве [22].

В работе [23] было изучено влияния различных добавок и связующих (рапсовая мука, порошок кофейных зерен, кора, порошок лигнина и сосновые шишки) на прессование брикетов из опилок древесины лиственницы и тюльпанового дерева. Показано, что при использовании в качестве связующего порошка лигнина получены топливные брикеты с высокими прочностными характеристиками.

В обзорной статье [24] продемонстрировано, что лигнин - дешёвый побочный продукт переработки древесины - может смешиваться с крахмалом и глицерином, давая более прочные и упругие материалы. В процессе измельчения лигнина образуются очень мелкие частицы, дающие хорошую адгезию с крахмалом, белками сои и их производными с образованием пространственных структур, что делает их привлекательными для использования в качестве связующих веществ.

Авторы работы $[25,26]$ изучали влияние крахмала и гуммиарабика на плотность и теплотворную способность брикетов из опилок. Установлено, брикеты с высокой теплотворной способностью $(33,09$ МДж/кг) и плотностью $(0,546$ г/см³ $)$ получены при использовании в качестве связующего крахмала.

Применяя глицерин в качестве связующего при прессовании соломы пшеницы, получили брикеты с пониженной зольностью и высокой теплотворной способностью $(17,9-18,7$ МДж/кг) только в присутствии опилок хвойных пород древесины [27].

В работе [28] брикеты получали из смеси рисовой соломы совместно с рисовыми отрубями и древесными опилками. Авторы предполагают, что плотность брикетов возрастает за счет образования сшивающих мостиковых связей между двумя растительными полимерами - лигнином и белком. При этом при температуре прессования $90{ }^{\circ} \mathrm{C}$ брикеты имеют достаточную теплоту сгорания, но низкую плотность, что сказывается на их прочности. Повышение тем-

$$
-505-
$$


пературы прессования до $150{ }^{\circ} \mathrm{C}$ приводит к получению высокопрочных брикетов с теплотой сгорания 18 МДж/кг.

Авторы изобретения [29] предлагают способ изготовления твердого биотоплива, включающий смешивание растительной биомассы с 0,1 - 10 масс. \% крахмала - связывающего агента, и насыщенные длинноцепочечные жирные кислоты, имеющие алифатическую цепь длиной по крайней мере в 12 атомов углерода, и / или их аналоги, имеющие температуру плавления или диапазон плавления в пределах от $40-95{ }^{\circ} \mathrm{C}$, а также в качестве связующего кроме крахмала использовали карбоксилметилцеллюлозу при следующем соотношении компонентов, масс. \%: крахмал от 4 до 8 или карбоксилметилцеллюлоза от 4 до 8 , вода менее 3 , измельченный древесный уголь - остальное, до 100. Применение данных связующих позволило повысить плотность топливного брикета с 500 до 900 кг/м³. Заявляемые технические решения расширяют ассортимент твердого топлива и обеспечивают создание экологически чистого брикетированного топлива с высокими энергетическими и прочностными характеристиками. Однако основным недостатком данных способов получения твердых биотоплив является применение в качестве связующих продуктов пищевого назначения, что может привести к увеличению их стоимости.

Для повышения теплоты сгорания, уменьшения зольности и увеличения водостойкости перед прессованием биомассу подвергали термической обработке при температуре $200-300^{\circ} \mathrm{C}$ без доступа воздуха (torrefaction). Затем полученную биомассу измельчали и прессовали, смешивая со связующим (крахмал, мука, карбоксилметилцеллюлоза, др.) [30] и без него [31]. Брикеты, полученные из термически обработанной древесины с использованием связующих, имели высокие прочностные качества, водостойкость и длительный срок хранения.

При торрефикации биомассы при температуре $200-320{ }^{\circ} \mathrm{C}$ без доступа воздуха получают «черные» брикеты (пеллеты) - модифицированное влагостойкое энергетическое топливо с небольшим содержанием влаги (до 3 \%), малыми объемом и массой (снижение на 30-50 \%), с незначительным содержанием серы и низким содержанием золы, способное конкурировать с углем. Оно может храниться на открытом воздухе и отгружаться в открытые контейнеры, что снижает себестоимость хранения и транспортировки по сравнению с обычными древесными гранулами [32].

Авторы работ с целью повышения пластифицирующих свойств и связующих качеств лигнина и лигноцеллюлозной биомассы в процессе прессования использовали активацию (взрывной автогидролиз) [33], химическую модификацию (окисление лигнинов периодатом калия) [34] и механоактивацию гидролизного лигнина [35]. Полученные топливные брикеты имели улучшенные прочностные и потребительские характеристики.

В работе [36] авторами было предложено для производства твердого биотоплива использовать связующим биомасло, полученное пиролизом биомассы или различных видов лигнина (крафт-лигнин, органосольвентный лигнин, лигнин черного щелока и др.). В результате проведенных исследований были получены топливные брикеты с повышенной гидрофобностью и высокой теплотой сгорания.

В работах $[37,38]$ авторами установлено, что низкомолекулярные лигнины, полученные в процессе окислительной каталитической делигнификации древесины пихты и осины в среде уксусной кислоты, имеют большое количество кислородсодержащих групп и могут быть ис- 
пользованы в качестве связующих при получении твердых биотоплив. Так, древесные брикеты, полученные с использованием уксуснокислотных лигнинов, имели прочность на сжатие 28 и $21 \mathrm{MПа} \mathrm{и} \mathrm{водопоглощение} 18$ и 15 \% для пихты и осины соответственно

Еще один растительный полимер представляет интерес с точки зрения применения его в качестве связующего при производстве твердых биотоплив - суберин, липофильное высокомолекулярное вещество из клеточных оболочек опробковевших тканей, содержание которого в бересте коры березы достигает $37-40 \%$.

В патенте [39] предложен способ выделения суберина и/или кутина, содержащихся в бересте березы, в смесь карбоновых кислот щелочным гидролизом без применения органических растворителей. Затем - дальнейшая переработка фракции, обогащенной цис-9,10-эпокси-18гидроксиоктадекановой кислотой, в моно-, олиго- и полиэфиры или соответствующие сложные эфиры, которые могут быть использованы в качестве топливных компонентов, пластификаторов, экологически чистых агентов для модификации древесины, связующих веществ для древесных композитов и твердых биотоплив.

Авторами $[40,41]$ были выделены субериновые кислоты гидролизом водными растворами $\mathrm{NaOH}$ и $\mathrm{Na}_{2} \mathrm{CO}_{3}$ из коры пробкового дуба с последующей их этерификацией для применения в качестве связующего агента при получении винных пробок, где наполнителем брали мелкодисперсную кору. Также в работе предложено использовать полученное связующее для производства твердых биотоплив.

В работе [42] показано, что суберин, выделенный из бересты березы гидролизом КОН, имеет повышенную реакционную способность за счет содержания реакционноспособных групп различной химической природы. Применяя суберин в качестве связующего, авторы получили брикеты с плотностью $850-862$ кг/м³ и пределом прочности на сжатие 23 29 МПа.

К особой категории твердого биотоплива можно отнести брикеты, полученные с использованием вторичного сырья в качестве связующих, наполнителей и улучшителей. Для изготовления таких брикетов применяют все виды отходов переработки лигноцеллюлозного сырья, а также бытовые отходы.

Так, авторы $[43,44]$ предлагают использовать в качестве связующего бытовые отходы (пластик) и наполнитель - материалы растительного происхождения (солома, торф, опилки и бумага). При прессовании на поверхности таких брикетов образуется защитная пленка, улучшающая их физико-механические свойства.

В ряде работ [45-49] предложено добавлять в пресс-массу угольную пыль или жидкие моторные топлива, в качестве связующего здесь выступают водоросли, воск или ил, что дает возможность расширить сырьевую базу утилизируемых отходов. Такие топливные брикеты могут быть использованы как индустриальные топлива.

\section{Масштабы производства}

\section{и направления использования твердых биотоплив}

В настоящее время большая часть стран Европейского союза, Америка и Канада в той или иной степени развивают альтернативную энергетику, поскольку понимают, что классические источники энергии исчерпаемы. В этом отношении биоэнергетика обладает явным преимуще-

$$
-507-
$$


ством, так как в качестве исходного сырья использует возобновляемую биомассу. Российская Федерация обладает крупнейшими в мире запасами биомассы, пригодной для применения в энергетических целях.

Приблизительно две трети топливных древесных гранул, производимых во всем мире, сжигается на электростанциях ЕС. Древесные топливные гранулы (пеллеты) получили широкое распространение в европейских странах благодаря различным формам поддержки производителей и потребителей. Среди таких мер - квоты на выработку ТЭЦ на твердом топливе «зеленого» электричества (электричества на основе биомассы), налоги на использование ископаемых энергоресурсов, субсидии на установку пеллетных котлов. Как следствие в Европе потребление пеллет в период 2004 - 2009 гг. выросло в 4,5 раза и продолжает расти. Аналогичные тенденции наблюдаются и в Северной Америке, где Канада и в особенности США перестают быть чистыми экспортерами пеллет в Европу и развивают собственные внутренние рынки [50].

Что касается производства топливных древесных гранул в ЕС, то за 2008 - 2010 гг. оно увеличилось на 20,5 \% и составило в 2010 г. 10,6 млн м³. За счет собственного производства удовлетворялось около 81 \% потребностей ЕС в топливных древесных гранулах [51]. По данным Европейской экономической комиссии $\mathrm{OOH}, 44$ \% всей древесной биомассы используется в Европе для производства энергии.

Крупнейшим производителем пеллет в ЕС является Германия с объемом производства в 2010 г. приблизительно 2 млн т в год и объемом производственных мощностей немного выше 3 млн т в год. По показателям объема мощностей для выпуска топливных древесных гранул за Германией следуют Швеция, Австрия, Франция и Польша [52]. За счет древесины удовлетворяется почти $20 \%$ общих потребностей в энергии в Швеции, Финляндии и Эстонии. В странах Балтии (Эстонии, Латвии и Литве) общий объем мощностей по выпуску древесных топливных гранул составляет 1,3 млн т в год.

Общемировой объем торговли всеми видами твердого топлива на базе биомассы (исключая древесный уголь) составил в 2010 г. 18 млн т (300 МДж). Более 90 \% этого показателя (273 МДж) приходилось на энергоносители на базе древесины, в том числе на топливные древесные гранулы (120 МДж), древесные отходы (77 МДж) и топливную древесину (76 МДж) (REN 21, 2012).

В целом, мировой спрос на пеллеты ежегодно растет на 15 \% и к 2020 г. должен составить 58 млн т, об этом говорится в пресс-релизе компании German Pellets GmbH, которая ссылается на Pöyry Management Consulting.

Производство топливных древесных гранул в Российской Федерации неуклонно растет, в 2012 г. его объем достиг 1 млн т (без учета агропеллет). Основная часть топливных древесных гранул, производимых в Российской Федерации, поставляется в Европу на экспорт, объем которого в 2012 г. составил приблизительно 850000 т в год. При этом поставки пеллет осуществляются преимущественно в промышленный сектор, так как на рынке пеллет для частного потребления в Европе доминируют местные производители. В 2012 г. Россия заняла пятое место в мире по экспорту пеллет после США, Канады, Латвии и Германии. К основным потребителям российских топливных гранул в течение нескольких лет относятся: Дания, Швеция, Финляндия, Латвия, Германия. 
В основном экспортные поставки пеллет и брикетов осуществляются из СЗФО, но также и из Центральной части России и Сибири (Красноярский край). К примеру, в 2011 г. 19,8 \% всего производства топливных гранул (пеллет) приходилось на Красноярский край, на территории которого действует два крупных завода - ДОК «Енисей» и «Новоенисейский ЛХК».

Внутреннее потребление брикетов растет в среднем на $2-4$ \% в год и составляет не более $10-15 \%$. В 2012 г. объем потребления пеллет на внутреннем рынке был на уровне 150000 т в год.

В России имеется огромный внутренний рынок для производства и использования топливных брикетов, что особенно актуально в условиях действия санкций на экспортирование продукции в страны ЕС, Америку и Канаду.

\section{Заключение}

За последние два десятилетия возрос интерес к использованию твердого биотоплива в качестве топлива из возобновляемого растительного сырья как альтернатива ископаемым видам топлива.

На основании анализа научно-технической информации можно отметить, что тематика выполняемых исследований в основном направлена на усовершенствование существующих методов получения брикетов и пеллет из растительных отходов. Много работ посвящено расширению сырьевой базы для производства твердого биотоплива за счет использования недревесной растительной биомассы и бытовых отходов.

Применение экологически безопасных связующих на основе растительных полимеров при производстве твердых биотоплив позволяет улучшить их потребительские характеристики за счет повышения прочности, водостойкости и теплотворной способности.

\section{Список литературы}

1. Булаткин Г. А. Производство биотоплива второго поколения из растительного сырья // Вестник Российской Академии наук. 2010. T. 80, № 5-6. C. 522-532. [Bulatkin G.A. Manufacturing of second generation biofuels from plant material // Journal of the Russian Academy of Sciences. 2010. T. 80, № 5-6, P. 522-532.(in Russ.)].

2. Орсик Л.С., Сорокин Н.Т., Федоренко В.Ф. Биоэнергетика: мировой опыт и прогнозы развития. М.: Росинформагротех, 2008. - 404 c.[Orsik L.S., Sorokin N.T., Fedorenko V.F. Bioenergy: global experience and development forecasts. - M .: Rosinformagroteh, 2008. -404 p. (in Russ.)].

3. Sikkema R., Steiner M., Junginger M., at al. The European wood pellet markets: current status and prospects for 2020 // Biofuels, Bioproducts and Biorefining. 2011. Vol. 5, № 3. P. 250278.

4. Варфоломеев С.Д., Моисеев И.И., Мясоедов Б.Ф. Энергоносители из возобновляемого сырья. Химические аспекты // Вестник РАН 2009. Т. 79, № 7. С. 595-604. [Varfolomeev S.D., Moiseev I.I., Myasoedov B.F. Energonositeli from renewable raw materials. Chemical aspects // Journal of the RAS 2009, T. 79, N 7, P 595-604 (in Russ.)].

5. Яшин М. Энергия природы // Леспроминформ. 2009. № 2. С. 124-127. [Yashin M. Energy of Nature // Lesprominform 2009. № 2. P 124-127(in Russ.)].

$$
-509-
$$


6. Сальников А.Л., Мучоно Р., Ряднов А.И., Давыдова С.А., Беспалова О.Н. К вопросу о производстве биопеллет в России // Естественные науки. 2011. №3 (36). C.90-97. [Salnikov A.L., Muchono R., Ryadnov A.I., Davidov S.A., Bespalova O.N. To the issue of biopellets manufacturing in Russia // Natural Sciences. 2011. №3 (36). P. 90-97. (in Russ.)].

7. Севастьянов С.Н. Биоэнергетика. Древесные (топливные) гранулы // Вестник ОГУ 2009. № 10 (104). C. 133-138. [Sevastyanov, S.N. Bioenergy. Wood (fuel) granules // Vestnik OGU 2009. Vol.10 (104), P. 133-138. (in Russ.)].

8. Гелес И.С. Древесное сырье - стратегическая основа и резерв цивилизации. Петрозаводск: Карельский научный центр РАН, 2007. 499 с. [Geles I.S. Wood raw materials - a strategic framework and reserve civilization. Petrozavodsk: Korelskiy Scientific Center of RAS, 2007. 499p. (in Russ.)].

9. Гудкова Е.А. Стратегия энергосбережения и повышения экологической безопасности регионов в фокусе перспективы использования пеллетного топлива // Строительство: наука и образование. 2012. № 3. C. 4. [Gudkova E.A. The strategy of energy saving and environmental security of the regions of focus prospects of using pellet fuel // Industrial Science and Education 2012, N 3, C 4. (in Russ.)].

10. Пат. РФ 2512210 (C2) МПК C10L5/00; C10L5/02; Способ по производству продукции, тепла и электроэнергии из торфа / Гревцев Н. В., Верхотуров И.М, Кирсанова И.В. и др.; заявл. 07.05.2012; опубл. 10.04.2014 [Pat. RU 2512210 (C2) IPC S10L5 / 00; S10L5 / 02; A process for the production of products, heat and electricity from peat / Grevtsev N.V., Verkhoturov I.M., Kirsanova I.V., et.al. .; appl. 07.05.2012; publ. 04.10.2014(in Russ.)].

11. Филичкина М.В., Абрамов В.В., Самошин Д.С., Фролов Г.А. Особенности опилок как наполнителя при производстве материалов из древесных отходов // Лесотехнический журнал 2013, № 2, C. 26-30. [Filichkina M.V., Abramov V.V., Samoshin D.S., Frolov G.A. Features sawdust as a filler in the production of materials from wood waste // Forestry Engineering magazine 2013. N 2. P. 26-30. (in Russ.)].

12. Кручинина Е.В., Заходякин Г.В. Стратегическое планирование цепи поставок в производстве биотоплива из отходов гидролизного лигнина с использованием компьютерных средств моделирования // Успехи в химии и химической технологии. 2011. T. XXV, № 13 (129). C. 7-10. [Kruchinina E.V., Zahodyakin G.V. Strategic planning of the supply chain in the production of biofuels from waste hydrolytic lignin using computer modeling tools // Successes in chemistry and chemical technology 2011. Vol.XXV, 13(129), C.7-10. (in Russ.)].

13. Зотова Е.В., Сафонов А.О., Платонов А.Д. Аналитическое исследование параметров, определяющих технологию производства древесных пеллет // Лесотехнический журнал. 2014. № 1. C. 127-132. [Zotova E.V.,Safonov A.O., Platonov A.D. Analytical study of parameters determinative the technology to produce wood pellets // Forestry Engineering magazine 2014. N 1, P. 127-132.(in Russ.)].

14. Stolarski M. J., Szczukowski S., Tworkowski J.Comparison of quality and production cost of briquettes made from agricultural and forest origin biomass // Renewable energy. 2013. Vol. 57. P. 20-26.

15. Imam S.H., Bilbao-Sainz C., Chiou B.-S. Biobased adhesive, gums, emulsions, and binders: current trends and future prospects // Jornal of Adhesion science and technology. 2013. Vol. 27. N 18 19. P. 1972-1997. 
16. Kaliyan N., Morey R.V. Natural binders and solid bridge type binding mechanisms in briquettes and pellets made from corn stover and switchgrass // Bioresource Technology. 2010. Vol. 101. P. 1082-1090.

17. Пат. РФ 2477305 C1, МПК C10L9/00, C10L5/44. Активные пеллеты / Брыкин Д. М., Брыкин М. А., Сердюк В. В., Сердюк Д. В., Ашкинази Л. А.; опубл. 10.03.2013. [Pat. RU 2477305 C1, IPC S10L9 / 00, C10L5 / 44. Active pellets / Brykin D.M., Brykin M.A., Serdyuk V.V., Serdyuk D.V., Ashkenazi L. A .; publ. 03/10/2013.(in Russ.)].

18. Пат. РФ 2413755 (C1) МПК C10L5/10; Топливный элемент - брикет, гранула / Кормилицын В.И., Петров А.В, Лобко В.П.; заявл. 24.02.2010; опубл. 10.03.2011. [Pat. RU 2413755 (C1) IPC S10L5 / 10; Fuel cell - briquettes, pellets / Kormilitsyn V.I., Petrov A.V., Lobko V.P.; appl. 24.02.2010; publ. 10.03.2011(in Russ.)].

19. Галяветдинова Н.Р., Насыбуллина А.Ф. Разработка технологии получения древесных топливных гранул с повышенной энергетической эффективностью // Актуальные направления научных исследований ХХІ века: теория и практика. 2014. T.2, № 3-4 (8-4). С. 27-31. [Galyavetdinova N.R., Nasybullina A.F. Development of technology for production of wood pellets with improved energy efficiency // Actual research trends of the XXI century: Theory and Practice. 2014. Vol. 2, № 3-4 (8-4). P 27-31. (in Russ.)].

20. Khitrin K.S., Fuks S.L., Khitrin S.V., et.al. Lignin utilization option and methods // Russian Journal of General Chemistry. 2012. Vol. 82, N5. P. 977-984.

21. Дейнеко И.П. Утилизация лигнинов: достижения, проблемы и перспективы // Химия растительного сырья. 2012. №1. C.5-20 [Deyneko I.P. Disposal of lignins: achievements, problems and prospects. Chemistry of plant raw materials 2012. Vol. 1. P. 5-20. (in Russ.)].

22. Byoung J. A., Hee-sun C., Soo M. L., et.al. Effect of binders on the durability of wood pellets fabricated from Larix kaemferi C. and Liriodendron // Renewable Energy. 2014. N 62. P. 18-23.

23. Sotannde O.A., Oluyege A.O., Abah G.B. Physical and combustion properties of briquettes from sawdust of Azadirachta indica // Journal of Forestry research. 2010. N 21(1). P. 63 - 67.

24. Tarasov D., Shahi Ch., Leitch M. Effect of additives on wood pellet physical and thermal characteristics: Reviw // ISRN Forestry. Vol. 2013, Article ID 876939, 6 p. [electronic resource] http:// dx.doi.org/10.1155/2013/876939.

25. Donghui Lu, Tabil Lope G., Wang D., Wang G. Experimental trials to make wheat straw pellets with wood residue and binders // Biomass and Bioenergy. 2014. Vol. 69. P. 287-296.

26. Chuen-Shii Chou, Sheau-Horng Lin, Wen-Chung Lu Preparation and characterization of solid biomass fuel made rice straw and rice bran // Fuel Processing Technology. 2009. Vol. 90. P. 980-987.

27. Mustelier N.L., Almeida M.E., Cavalheiro J., et.al. Evaluation of pellets produced with undergrowth to be used as biofuels // Waste Biomass Valor. 2012. Vol. 3. P. 285-294.

28. Пат. РФ 2484125 (C1) МПК C10L5/44, C10L5/14, C10F7/06. Способ изготовления топливных брикетов из биомассы / Табакаев Р. Б., Заворин А. С., Казаков А. В., Плахова Т. М.; опубл. 10.06. 2013. [Pat. RU 2484125 (C1) IPC S10L5 / 44, C10L5 / 14, C10F7 / 06. Method of manufacturing fuel pellets from biomass / Tabakaev R.B., Zavorin A. C.,Kazakov A.V., Plakhova T. M. ; publ. 10.06. 2013.(in Russ.)].

29. Pat. WO 2011062488 A1 IPC C10L5/44 Fuels pellets, their preparation and use / Meneva B.V., Renirie J.G., Van Der Meijden J. A. A., Van Soest J. J.G., Plijter J.J.; publ. 26.05.2011. 
30. Пат. РФ 2378325 (C2) МПК C10L5/10; C10L5/12; C10L5/14 Топливный брикет / И.М. Мазурин, Б.П. Пономаренко; заявл. 27.08.2009; опубл. 10.01.2010. [Pat. RU 2378325 (C2) IPC S10L5 / 10; S10L5 / 12; S10L5 / 14 Fuel briquettes / Mazurin I.M., Ponomarenko B.P.; appl. 27.08.2009; publ. 10.01.2010.(in Russ.)].

31. Stelte, Wolfgan. Pelletizing properties of torrefied spruce / Wolfgan Stelte [et. al.] // Biomass and Bioenergy. 2011. №35. P. 4690-4698.

32. Шегельман И.Р., Васильев А.С Анализ путей повышения конкурентоспособности энергетической биомассы // Инженерный вестник Дона. 2013. Т. 26, № 3(26). С. 22-29. [Shegelman I.R.,Vasiliev A.S. Analysis of ways to enhance the competitiveness of energy biomass. Engineering messenger Don 2013. V. 26, № 3 (26). P. 22-29. (in Russ.)].

33. Веприкова Е.В., Чунарев Е.Н., Щипко М.Л., Чесноков Н.В., Кузнецов Б.Н. Исследование связующих свойств автогидролизованной древесины осины // Химия растительного сырья 2012. № 4. C.49-54. [Veprikova E.V., Chunarev E.N., Shchipko M.L., Chesnokov N.V., Kuznetsov B.N. Investigation of binding properties of autohydrolyzed aspen wood // Chemistry of plant raw materials 2012. Vol.4, P. 49-54. (in Russ.)].

34. Gosselink, Richard J.A. Effect of periodate on lignin of wood adhesive application / J.A.Richard Gosselink et. al. // Holzforschung 2011, Vol. 65 (2), P. 155-162.

35. Евдокимов Н.В., Александров А.В. Разработка технологии брикетирования древесных отходов с использованием связующей композиции на основе механоактивированного гидролизного лигнина // Актуальные направления научных исследований XХІ века: теория и практика. 2014. № 2 - 3 (7-3). C.65-68. [Evdokimov N.V., Aleksandrov A.V Development of technology for briquetting wood waste using the binder composition on the basis of mechanically hydrolytic lignin. Actual research directions of the XXI century: Theory and Practice 2014, № 2 - 3 (7-3). P. 65-68. (in Russ.)].

36. Pat. US 20130031830 (A1) IPC C10L11/06; C10L5/04 Method for producing binders and combustible composite materials and composition produced therefrom / Philip H. Steel, Venkata K. Penmetsa; publ. 07.02.2013.

37. Kuznetsov B.N., Sudakova I.G., Celzard A., Garyntseva N.V., Ivanchenko N.M., Petrov A.V. Binding properties of lignins obtained at oxidative delignification of wood and straw // Journal of Siberian Federal University. Chemistry. 2011. Vol. 1(4). P.3-10.

38. Кузнецов Б.Н., Чесноков Н.В., Гарынцева Н.В., Яценкова О.В. Интегрированная каталитическая переработка древесины осины в жидкие и твердые биотоплива // Журнал СФУ. Химия. 2013. № 3 (6). С. 286-298. [Kuznetsov B.N., Chesnokov N.V., Garyntseva N.V., Yatsenkova O.V. Integrated catalytic processing of aspen wood into liquid and solid biofuels // Journal of Siberian Federal University. Chemistry. 2013. № 3 (6). P. 286-298. (in Russ.)].

39. Pat. US 20110319504 (A1) IPC C08G63/49; C10M105/34; C10L1/188; C09D11/02; A61K8/92; C09K3/00; C07C67/02; C09D191/00 Method for the manufacture of oligo- and polyesters from a mixture of carboxylic acid obtained from suberin and/ or cutin and use thereof / S. Koskimies, J. Hulkko, P. Pitkänen, N. Heiskanen, J. Yli-Kauhaluoma, K. Wähälä.; publ. 29.12.2011.

40. Pat. WO 2010093320 (A1) IPC C07C51/42; C07C59/305; C07C59/58 The method for separating from suberin and/or cutin containing plants, a solid and/or oil fraction enriched in cis-9,10-epoxy-18hydroxyoctadecanoic acid. / T. Inversen, H.Nilsson, A. Olsson; publ.19.08.2010. 
41. Gil Luis Cork composites: A Review / Materials 2009, Vol.2, P. 776-789.

42. Судакова И.Г., Гарынцева Н.В., Иванов И.П. и др. Выделение и применение суберина из бересты коры березы // Журнал Сибирского федерального университета. Химия. 2012. № 2(5). C. 168-177 [Sudakova I.G., Garyntseva N.V., Ivanov I.P., et al. Isolation and application of suberin of the outer layer birch bark // Journal of Siberian Federal University. Chemistry. 2012. № 2 (5). P. 168177 in Russ.)].

43. Pat. UA 95423 (C2) IPC C10L5/48; Y02E50/10; Y02E50/30 Process for preparation of solid fuel and solid fuel / I.Y. Tsyhankov, M.O. Sahalevych; priority 20.10.2010; publication 25.07.2011.

44. Pat. US 8337756 C10L5/44 Solidification processing method and solidification processing apparatus / Yoshikazu Kobayashi; publ. 25.12.2012.

45. Pat. KR 101391125 (B1) IPC Y02E50/30 The fuel processing system by using organic waste and waste fiber / Hwang Jae Sik, Choi Byung Joon, Kang Ki Suk, et.al.; publ. 02.05.2014.

46. Pat. CN 102618338 (A) IPC B09B3/00; C10L1/32 Technology and apparatus for producing slurry and solid fuel from garage and biomasses / Hanping Chen; publ. 01.08.2012.

47. Пат. РФ 2507241 (C2) МПК C10L5/00; C10L5/14; C10L5/36; C10L5/44 Брикет на основе спрессованного лигноцеллюлозного тела, пропитанного жидким топливом / Фуасак Г., Плион П., Фише В., Табе Ф.; опубл. 20.02.2014. [Pat. RU 2507241 (C2) IPC S10L5 / 00; S10L5 / 14; S10L5 / 36; S10L5 / 44 Briquette on the basis of compacted lignocellulosic body impregnated with liquid fuel. / Fuasak G. Plion P.,. Fishe V., Taba F .; appl. 20.12.2010; publ. 02.20.2014 (in Russ.)].

48. Пат. РФ 2510660 (C2) МПК C10L5/40; C10L5/04; C10L5/10; A01K1/015; A01K1/035; B01D15/00; B01J20/22 Пеллеты и брикеты из спрессованной биомассы. / Майкл.Б.Майерз, Джей. Дж.Худ; заявл. 25.05.2010; опубл. 10.04.2014.

[Pat. RU 2510660 (C2) IPC S10L5 / 40; S10L5 / 04; S10L5 / 10; A01K1 / 015; A01K1 / 035; B01D15 / 00; B01J20 / 22 Pellets and briquettes from compressed biomass / M.B. Mayerz, J.J. Hud; appl. 25.05.2010; publ. 04/10/2014 (in Russ.)].

49. Пат. РФ 2402598 (C1) МПК C10L5/44 Способ получения твердого биотоплива из древесного сыпучего сырья / А.О.Сафонов, О.Ф.Трещева; заявл. 25.05.2009; опубл. 27.10.2010. [Рat. RU 2402598 (C1) IPC S10L5 / 44 A method of producing solid biofuels from wood bulk material / A.O.Safonov, O.F.Trescheva; appl. 25.05.2009; publ. 27.10.2010 (in Russ.)].

50. Cocchi M., et.al. Sustainable Bioenergy Trade /IEA Bioenergy 2011, 190 p.

51. ЕЭК ООН/ФАО Ежегодный обзор рынка лесных товаров, 2011-2012 годы // Женевское исследование по сектору лесного хозяйства и лесной промышленности. № 30.240 с. [UNECE / FAO Annual Forest Products Market Review, 2011-2012, Geneva research on forest and timber industry. № 30. 240p.(in Russ.)].

52. Taberner P. Big in the Baltics // Biomass Magazine. 2011. 31 October. 